\title{
Differential influence of two acanthocephalan parasites on the antipredator behaviour of their common intermediate host
}

\author{
NICOLAS KALDONSKI, MARIE-JEANNE PERROT-MINNOT \& FRANK CÉZILLY \\ Equipe Ecologie-Evolutive, UMR CNRS 5561 Biogéosciences, Université de Bourgogne
}

\begin{abstract}
Fish acanthocephalans can modify the antipredator behaviour of their intermediate hosts in response to cues from fish predators. However, it is still unclear whether such behavioural changes are adaptive, or are just the consequence of infection. We addressed this question through studying two acanthocephalans, Pomphorhynchus laevis and Polymorphus minutus, and their intermediate host, the amphipod Gammarus pulex. Pomphorhynchus laevis completes its cycle in a freshwater fish, whereas P. minutus exploits waterbirds as final hosts. We first assessed vulnerability of infected and uninfected gammarids to predation by bullheads, Cottus gobio. Pomphorhynchus laevis-infected gammarids were more susceptible to predation than uninfected ones when a refuge was available, whereas no selective predation on $P$. minutus-infected individuals was recorded, independently of refuge availability. We then quantified refuge use when a bullhead was present in an enclosure or when the enclosure was empty. Individuals of each group significantly increased refuge use in the presence of a bullhead. However, a larger proportion of P. laevis-infected gammarids remained out of the refuge in the presence of a predator, compared with uninfected controls, whereas no such effect was observed in P. minutus-infected ones. Finally, we assessed reaction to bullhead olfactory cues, using a Y-maze apparatus. Pomphorhynchus laevis-infected gammarids spent significantly more time in the predator-scented arm, whereas the reverse was observed in uninfected ones. Polymorphus minutus-infected individuals, however, did not differ from uninfected controls. We discuss our results in relation with the adaptiveness of host manipulation by parasites.
\end{abstract}

Keywords: Acanthocephalan; antipredator behaviour; Cottus gobio; host-manipulation; olfaction; Polymorphus minutus; Pomphorynchus laevis; parasites

Several species of parasites critically rely on a phase of trophic transmission from an intermediate host to a final host to complete their complex life cycle (Parker et al. 2003). Any alteration in the phenotype of the intermediate host that would result in increased vulnerability to predation by final hosts is thus supposed to benefit the parasite. Over the last 30 years, empirical evidence demonstrating the ability of some parasites to manipulate the phenotype of their intermediate hosts has accumulated (Moore 2002; Thomas et al. 2005). Parasites may change host appearance (Camp \& Huizinga 1979; Oetinger \& Nickol 1981; Bakker et al. 1997; Fuller et al. 2003), microhabitat choice (MacNeil et al. 2003;

Correspondence: F. Cézilly, Equipe Ecologie-Evolutive, UMR CNRS 5561 Biogéosciences, Université de Bourgogne, 6 Blvd Gabriel, 21000 Dijon, France (email: frank.cezilly@u-bourgogne.fr).
Miura et al. 2006), behaviour (Bethel \& Holmes 1973; Cézilly et al. 2000) and physiology (Plaistow et al. 2001; Tain et al. 2006). However, only a few empirical studies have convincingly demonstrated that changes in the phenotype of infected hosts, rather than a general decrease in stamina, are indeed responsible for the increased vulnerability of intermediate hosts to predation by appropriate final hosts (Cézilly \& Perrot-Minnot 2005).

A particularly efficient way for trophically transmitted parasites to achieve specificity in manipulation could be to target the antipredator behaviour of their intermediate hosts (Hechtel et al. 1993; Berdoy et al. 2000). Many prey species have evolved adaptations to reduce predation risk, such as morphological structures, chemical repellents, crypsis and avoidance behaviours (Endler 1986; Sih 1987; Dodson et al. 1994; Kats \& Dill 1998). In the presence of a specific predator, prey may alter their behaviour so that they are more difficult to encounter, detect or capture 
(Lima 1998). In the aquatic environment, in particular, olfactory assessment of predation risk can occur at distance and allow prey to react to minimize the risk of encounter with predators (Peacor \& Werner 1997; Turner 1997; Peckarsky \& McIntosh 1998; Huhta et al. 2000; Wisenden 2000). Aquatic prey organisms respond to predator-associated chemical cues in a number of ways, most often by reducing activity level and increasing the use of refuges (for a review, see Kats \& Dill 1998). In this context, any change induced by parasite on chemically based predator recognition might be a fine-tuned strategy to reach a final host.

Recently, two independent studies (Baldauf et al. 2007; Perrot-Minnot et al. 2007) have provided direct evidence for manipulation of the antipredator behaviour of the crustacean amphipod Gammarus pulex by acanthocephalan parasites. Baldauf et al. (2007) first showed that gammarids infected with the fish acanthocephalan parasite Pomphorhynchus laevis were attracted to the smell of a perch Perca fluviatilis, whereas uninfected individuals were repulsed by the same odour, independently of visual cues. Perrot-Minnot et al. (2007) went further by showing that infection of $G$. pulex with the congeneric parasite Pomphorhynchus tereticollis resulted in both increased vulnerability to predation by bullheads, Cottus gobio, in the field, and reversed antipredator behaviour (as measured by use of refuges and reaction to chemical cues from the predator). However, whether such an alteration of host antipredator behaviour is peculiar to fish parasites, or is just a by-product of infection with acanthocephalans remains so far unclear.

We addressed this question in a series of experiments using two species of acanthocephalan parasites and their common intermediate host, the crustacean amphipod G. pulex. In Burgundy (eastern France), both P. laevis and Polymorphus minutus, a bird acanthocephalan, exploit the amphipod G. pulex as intermediate host. Each parasite is known to induce specific behavioural modifications in their intermediate host, with $P$. laevis affecting mainly phototactism, whereas $P$. minutus reverses geotactism (Cézilly et al. 2000). Pomphorhynchus laevis is known to establish in several fish species, including the bullhead (Rumpus 1975; Kennedy 1999). By contrast, being predated by a bullhead represents a dead-end for $P$. minutus. We first compared in a series of controlled experiments the vulnerability of $P$. laevis-infected gammarids and P. minutus-infected ones to predation by bullhead, which is both an appropriate final host for the parasite and one of the main predators of amphipods in freshwater ecosystems (Andersson et al. 1986; Andersen et al. 1993; MacNeil et al. 1999). Second, as G. pulex is known to show marked antipredator behaviour in response to predators' cues (Williams \& Moore 1985; Holomuzki \& Hoyle 1990; Wudkevich et al. 1997; Dahl et al. 1998; Baldauf et al. 2007; Perrot-Minnot et al. 2007), we assessed the influence of each parasite on the antipredator behaviour of their common intermediate host using two different methods.

\section{METHODS}

Uninfected, P. laevis- and P. minutus-infected G. pulex were collected from July to September in 2004 and 2005 in the river Ouche at Dijon (Burgundy, eastern France) using the kick sampling method (Hynes 1954). Infected gammarids can be readily distinguished from uninfected ones since parasites can be seen through the host's translucid cuticle as a yellow-orange dot for $P$. laevis and as an orange-red dot for P. minutus. Adult males were selected for the experiments, within sizes ranging from 11 to $15 \mathrm{~mm}$ long. They were maintained in several separate tanks, well aerated, and filled with dechlorinated tap water. Gammarids were fed with leaves and fish food, for at least 1 week of acclimatization to room and water condition before experiments. Bullheads, with a size ranging from 75 to $85 \mathrm{~mm}$ were caught with a dipnet, kept in the room for 1 month before the experiments and fed with gammarids. They were starved for $24 \mathrm{~h}$ prior to the experiments. Room temperature was kept constant at $15^{\circ} \mathrm{C}$ with a light:dark cycle of $12: 12 \mathrm{~h}$.

\section{Selectivity of Bullheads towards Infected Preys}

The selectivity of bullheads towards gammarids preys infected with either fish or bird acanthocephalans was assessed during predation tests performed in a controlled lab-microcosm. Predation tests were carried out in aquaria measuring $32 \times 20 \times 20 \mathrm{~cm}$, filled with 7-litre of dechlorinated and oxygenated tap water. A simple habitat set-up consisted of washed river sand substrate, whereas a complex habitat set-up was composed of a piece of air brick $(21.5 \times 10 \times 5 \mathrm{~cm})$ placed on the sand substrate plus two Apiacea plants; both air brick and plants could be used by gammarids as refuges. Aquaria were screened with brown plastic on four sides and at the bottom to avoid any lateral disturbance. Overhead solar spectra fluorescent tubes (JBL Solar Natur, $25 \mathrm{~W}$ and $9000 \mathrm{~K}$ ) provided an illumination of 700 lux. This light intensity is equivalent to dawn or dusk light conditions, under which bullheads show peak predatory activity in the field (Andreasson 1969). Predators were offered a 30:70 infected:uninfected prey ratio. To that end, we introduced 42 uninfected gammarids and either $18 \mathrm{P}$. laevis- or $18 \mathrm{P}$. minutus-infected gammarids in the aquarium $15 \mathrm{~min}$ before introducing one individual bullhead. Each individual bullhead was used for only one test. Following preliminary experiments, the duration of each trial was set at $90 \mathrm{~min}$. At the end of each trial, the bullhead and the remaining prey were removed, surviving gammarids counted, and we recorded the percentage of surviving infected prey. All material was then carefully rinsed with tap water. Bullheads were released in their habitat of origin at the end of the experiments.

Following Seppälä et al. (2004), differential of predation between the two prey types was assessed using the probabilistic approach described in Manly (1974) which allows for the depletion of prey during the course of the trial, and thus for changes in the proportions of available prey classes as prey are eaten. Only experiments where more than six preys had been eaten were kept for analysis (see Manly 1974). To determine predator selectivity for infected gammarids, we calculated Manly's alpha $\left(\alpha_{i}\right)$ for variable prey population using the equation 


$$
\alpha_{i}=\frac{\log _{e} p_{i}}{\sum_{j=1}^{m} p_{j}}
$$

where $\alpha_{i}$ is the Manly's alpha (preference index) for prey type $I, p_{i}$ and $p_{j}$ are the proportion of prey $i$ or $j$ remaining at the end of the trial, and $m$ is the number of prey types. Manly's selectivity index ranges from 0 (when only uninfected prey are eaten) to 1 (when only infected prey are eaten), with a value of 0.5 for absence of preference. Observed values of $\alpha_{i}$ were compared with a situation of equal vulnerability $\left(\alpha_{i}=0.5\right)$ using a two-tailed nonparametric sign test, since the assumptions of parametric tests were not met.

\section{Influence of Infection on Refuge Use}

Bullhead are known to emit both acoustic and olfactory signals. Acoustic 'knocking' sounds are produced by the males to attract a female (Ladich 1989) and have a territorial function in the sexual season, but are rare compared with chemical cues associated with mucus and urine production. Gammarids are known to respond to these stimuli, but in greater proportion to the latter (Andersson et al. 1986). The typical reaction is a hiding behaviour under stones or any refuge around, and diminishing activity (Wudkevich et al. 1997).

Experiments were performed in the same experimental set-up than previously, except that this time only the piece of air brick was made available as refuge. For each test, 10 individual gammarids of the same type (uninfected, $P$. laevis or $P$. minutus infected) were placed in the aquarium. The number of gammarids outside the refuge was then recorded after $90 \mathrm{~min}$, either in a predatorfree situation, or when a single bullhead had been placed in a microperforated enclosure inside the aquarium. Since data were not normally distributed, we used a KruskalWallis test, followed by post hoc tests for comparison with a control (Siegel \& Castellan 1988), to assess the effect of each parasitic infection on the use of refuge, in the presence or in the absence of a predator. MannWhitney $U$ tests were subsequently used to compare the use of refuge in the absence versus in the presence of a predator within each group (uninfected, $P$. laevis or P. minutus infected).

\section{Response to Fish Odour}

Water is an excellent medium for the solubilization and dispersal of chemical signals, and the antipredator response of both vertebrate and invertebrate prey to predator chemical cue is well known to confer a fitness benefit (Wisenden et al. 1997). Response to fish odour is thus a critical component of susceptibility to predation. Experiments were carried out in a Y-maze olfactometer made of clear glass and fitted to a peristaltic pump, as described in Perrot-Minnot et al. (2007). Experiments were run between 0900 and 1700 hours. All observations were done behind a curtain to minimize interference with the observer. Bullhead-conditioned water was obtained through placing a single fish for $24 \mathrm{~h}$ into a clean aquarium with
$250 \mathrm{ml}$ of dechlorinated tap water per fish centimetre. Total length of bullheads ranged from 80 to $90 \mathrm{~mm}$. At the end of each trial, a small quantity of tap water was added to the aquarium to re-fill it from the lost volume. Oxygenated and dechlorinated tap water was used as control water.

Each experimental trial lasted 11 min. After a preflow time of $1 \mathrm{~min}$, a single specimen of $G$. pulex was introduced in the starting area in the 4 downstream $\mathrm{cm}$ of the Y-maze. Following a 5-min acclimatization period, scented water was connected to the olfactometer, the door was simultaneously removed, releasing the gammarid that was expected to swim against the mild current of the inflow due to rheotaxis. Gammarid behaviour was directly observed for 5 min using a Psion Workabout. After each run, the test gammarid was removed and the olfactometer and connecting tubes were carefully rinsed with tap water. The inflow arm of the treatment water was switched after every five replicates to control for any side preference, at which moment the olfactometer was cleaned with ethanol and tap water. We used a different gammarid for each replicate and a different bullhead every 30 gammarids (such that 10 gammarids of each group were tested with a single bullhead). Trials where gammarids showed no movement for 2 min following door-lifting or spent less than $20 \%$ of total time in the two inflow arms were not considered in the analysis. For each trial, the proportion of total time spent in the treated arm was calculated. Arcsine square root-transformed proportions met normality (Shapiro-Wilk test), thus allowing the use of parametric tests. We calculated 95\% confidence intervals around the mean proportion of time spent in the scented arm. Comparison between uninfected, P. laevis- and P. minutus-infected gammarids was made using an analysis of variance (ANOVA; Sokal \& Rohlf 1995).

All statistical tests were performed with JMP statistical software v. 5.0 (SAS Institute Inc., Cary, NC, U.S.A.).

\section{RESULTS}

\section{Selectivity of Bullhead towards Infected Preys}

A total of 823 gammarids were eaten by 62 different bullheads in the microcosm experiments. Figure 1 shows variation in specificity in predation towards infected prey in relation to parasite species and presence/absence of refuges, as assessed from Manly's $\alpha$ preference index. Selective predation on parasitized prey was significant in the case of $P$. laevis infection only when a refuge was available (Sign test, without refuge: $P=0.4545$; with refuge: $P=$ $0.0180)$. By contrast, $P$. minutus-infected prey did not differ from uninfected ones in vulnerability to predation by bullheads, both in the absence $(P=1.000)$ and presence of a refuge $(P=0.6072)$. Vulnerability of $P$. laevis-infected gammarids was higher than that of $P$. minutus-infected ones only in the presence of refuge (Mann-Whitney $U$ test: with refuge: $U=25.5, N_{P \text {. laevis }}=N_{P \text {. minutus }}=15, P=$ 0.0003; without refuge: $U=68.5, N_{P . \text { laevis }}=N_{P . \text { minutus }}=16$, $P=0.07)$. 


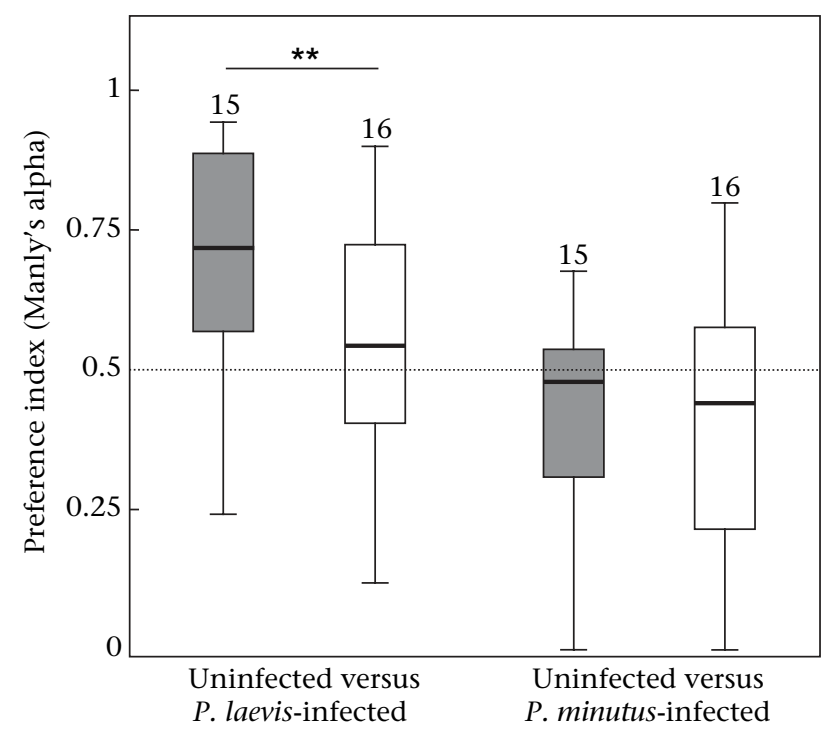

Figure 1. Box plot indicating median, interquartile range and range for differential predation on infected versus uninfected Gammarus pulex as assessed from Manly's $\alpha$ preference index (light bars: no refuge available; dark bars: refuge available). Values above the dashed line indicate overconsumption of infected prey. Numbers above the bars are sample size. ${ }^{*} p<0.05 ;{ }^{* *} P<0.01 ;{ }^{* \star *} p<0.001$.

\section{Influence of Infection on Refuge Use}

Infection status had no significant influence on refuge use in the absence of a predator (Kruskal-Wallis test: $\mathrm{H}_{2}=3.43, \mathrm{P}=0.18$; Fig. 2). The presence of a predator induced a decrease in the number of gammarids out of the refuge (Mann-Whitney $U$ test: uninfected: $U=0$, $N_{\text {without bullhead }}=N_{\text {with bullhead }}=8, P<0.001 ; P$. laevis infected: $U=12, \quad N_{\text {without }}$ bullhead $=N_{\text {with }}$ bullhead $=8$, $P=0.033 ; P$. minutus infected: $U=5, N_{\text {without bullhead }}=$ $N_{\text {with bullhead }}=8, P=0.0037$ ), but not to the same extent. Indeed, refuge use in the presence of a predator differed

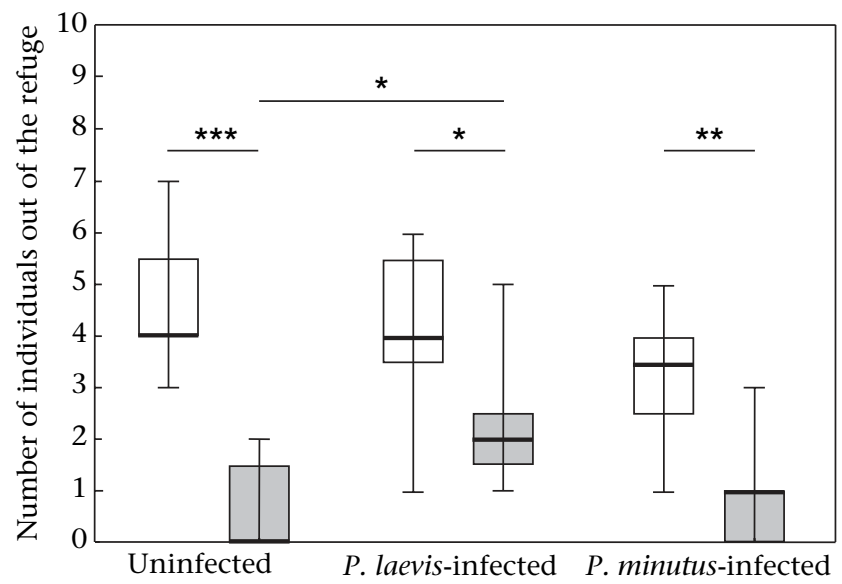

Figure 2. Box plot indicating refuge use by uninfected, Pomphorhynchus laevis-infected, and Polymorphus minutus-infected Gammarus pulex in a microcosm setting. Light bars: without predator; dark bars: with predator ( $N=8$ replicates for each group). Groups connected by above lines are significantly different (see text for methods). ${ }^{*} P<0.05 ;{ }^{* *} P<0.01 ;{ }^{* *} P<0.001$.

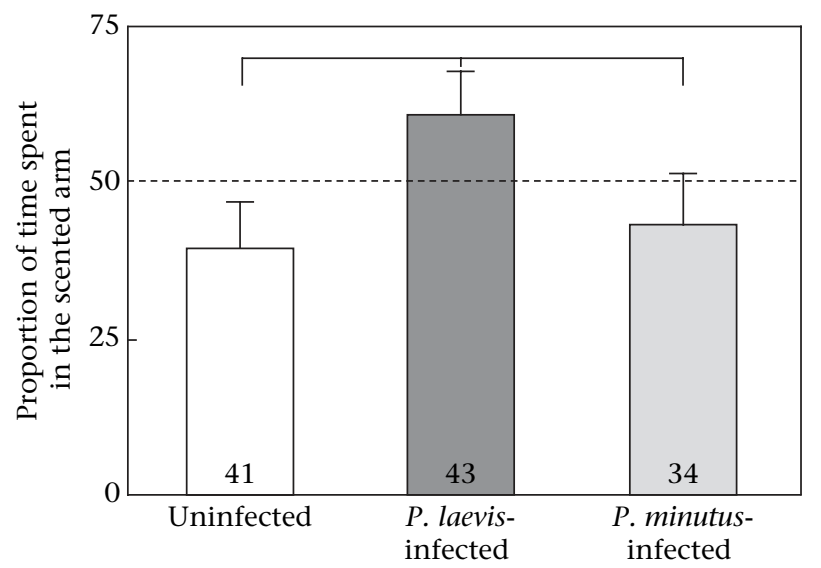

Figure 3. Time spent by uninfected, Pomphorhynchus laevis-infected, and Polymorphus minutus-infected gammarids in the predatorscented arm in the Y-maze experiment. Dashed line represents random visit of control and stimulus arms. Means are given $\pm 95 \%$ confidence interval. Numbers in the bars are sample size.

between the three groups (Kruskal-Wallis test: $H_{2}=8.25$, $P=0.016$ ). This difference was actually due to a higher number of $P$. laevis-infected individuals out of the refuge compared with uninfected (comparison with uninfected control: $q=2.891, P<0.01$ ), whereas $P$. minutus-infected individuals and uninfected did not differ $(q=0.535, P>$ $0.05)$.

\section{Response to Fish Odour}

Response to fish odour in a Y-maze olfactometer differed significantly between uninfected and infected gammarids (ANOVA, $F_{2.117}=9.58, P<0.0001$; Fig. 3 ). Percentage of time spent by uninfected gammarids was significantly lower in the arm with scented water than expected under the assumption of random choice (time spent in the scented arm over the total time spent in the inflow arms: mean and 95\% confidence interval on backtransformed data $=39.2 \%(32.3-46.4 \%), N=41$; Fig. 3). By contrast, $P$. laevis-infected gammarids spent significantly more time in the arm with bullhead-conditioned water (mean and 95\% confidence interval on back-transformed data $=60.6 \%(53.5-67.4 \%), N=43$; Fig. 3$)$. The difference between the two groups was significant (leastsquare contrast post hoc comparison: $F_{1.115}=17.00$, $P<0.0001)$. Polymorphus minutus-infected individuals spent on average $43.1 \%$ (95\% confidence interval on back-transformed data $=35.2-51.2 \%, N=34$ ) of their time in the predator-scented arm, and did not differ from uninfected individuals (least-square contrast post hoc comparison: $F_{1.115}=0.48, P=0.49$ ). By contrast, $P$. minutus-infected individuals spent significantly less time than $P$. laevis-infected ones within the scented arm (least-square contrast post hoc comparison: $\left.F_{1.115}=10.34, P=0.002\right)$.

\section{DISCUSSION}

Overall, our results, together with those of previous studies (Hechtel et al. 1993; Bakker et al. 1997; Wellnitz 
et al. 2003; Baldauf et al. 2007; Perrot-Minnot et al. 2007), show that the modification of the antipredator behaviour of crustacean intermediate hosts by fish acanthocephalans may contribute to increase in the trophic transmission of parasites to fish final hosts. In addition, the present study indicates that, in the same conditions, gammarids infected by a bird acanthocephalan do not show increased vulnerability to a fish predator. Therefore, taken together, our results suggest that the alteration of the antipredator behaviour of intermediate hosts might ensure trophic transmission to appropriate final hosts, thus providing evidence for some degree of specificity in parasitic manipulation. Such specificity in manipulation supports the hypothesis of adaptive manipulation according to one of the key criteria of fitness gain proposed by Poulin (1995).

Compared with previous studies on the influence of parasites on hosts' reaction to predators (i.e. Hechtel et al. 1993; Berdoy et al. 2000; Wellnitz et al. 2003; Baldauf et al. 2007; but see Perrot-Minnot et al. 2007), the present study combined detailed analysis of antipredator behaviour with predation tests in microcosms. One of the major criticisms of predation experiments made in microcosms is the use of unrealistic ratio of parasitized prey, hence favouring their overconsumption (Nickol 2005; Thomas et al. 2005). Indeed, in most previous studies (e.g. Bethel \& Holmes 1977; Camp \& Huizinga 1979; Bakker et al. 1997) infected and uninfected preys were offered in equal proportions, such that infected preys were overrepresented compared with their natural prevalence. By contrast, in the present study, the proportions of infected and uninfected prey (30:70) were closer to field prevalence of infected gammarids in the drift (L. Bollache et al., unpublished data).

However, the present study relied on naturally infected prey items instead of experimentally infected individuals. It might therefore be argued that gammarids behaved differently for reasons unrelated to parasitism, and that the odd behaviour was actually the cause rather than the consequence of infection with acanthocephalans. Such an explanation is unlikely for two different reasons. The first one is the fact that the results are different for the two species of parasites. The second one corresponds to the fact that changes in the behaviour of intermediate hosts infected with acanthocephalans happen only after the parasite has reached the cystacanth stage (i.e. the stage at which the parasite becomes infective to the definitive host), whereas intermediate hosts infected with immature parasites show no change in behaviour (F. Cézilly \& M.-J. Perrot-Minnot, unpublished results; see also Bethel \& Holmes 1974).

One particular interest of our results is the strong congruence between the results of predation experiments and those related to the use of refuge and response to predator chemical cues by uninfected and infected prey. No difference was observed in the use of refuge between uninfected gammarids, P. laevis-infected, and P. minutusinfected ones in the absence of a predator. A difference in the use of refuge was only observed in the presence of a predator. Although P. laevis-infected individuals increased their use of refuges in the presence of a predator, they did so with less intensity than uninfected and
P. minutus-infected ones. Accordingly, differential predation on $P$. laevis-infected individuals was significant only when refuges were made available. The importance of reaction to predator chemical cues is further demonstrated by the experiments using the Y-maze oflactometer. Considered alone, the lesser use of refuge by $P$. laevis-infected gammarids in the presence of predator cues, compared with $P$. minutus-infected and uninfected ones, is open to alternative explanations. Infection with $P$. laevis may render gammarids less able to detect fish odour, or infected gammarids may remain able to detect it but not respond accordingly (see Wellnitz et al. 2003). Here, however, the use of a distant system of chemical predator perception allowed us to separate chemical cues from other factors. The significant attraction of $P$. laevis-infected individuals towards chemical cues from a bullhead clearly shows that infected individuals are indeed able to perceive chemical stimuli, but differ from uninfected ones in their response to predator scent (see also Perrot-Minnot et al. 2007).

Infection by acanthocephalans can result in various alterations of the host phenotype (Bakker et al. 1997; Cézilly et al. 2000; Baldauf et al. 2007; this study) that may all contribute to increased vulnerability to predation by final hosts. It has been previously shown that $P$. laevis reverses photokinesis in $G$. pulex, whereas $P$. minutus strongly alters geotaxis (Cézilly et al. 2000). Both alterations of host behaviour may contribute to increase in appropriate transmission to appropriate final hosts. However, the effect of manipulating parasites on host responses to light and gravity may not be sufficient to explain differential susceptibility in the field (Bakker et al. 1997; Levri \& Fisher 2000). Other variables, such as cues from predators and increased conspicuousness of infected hosts (Camp \& Huizinga 1979; Oetinger \& Nickol 1981; Fuller et al. 2003), may be important and interact with physical cues to determine the behaviour of infected hosts. In this respect, the absence of differential predation between $P$. laevis-infected individuals and uninfected ones in the absence of refuge seems at first sight to contradict the results of Bakker et al. (1997) who found that the change in appearance of infected individuals (due to the orange cystacanth being visible through the host's translucid cuticle) contributed directly to their increased vulnerability to a fish predator. However, the two studies used different predator species. Bakker et al. (1997) studied predation by sticklebacks, Gasterosteus aculeatus, which are active predators and in which females show a marked sensory bias for red-orange coloration in relation to male nuptial ornaments (Smith et al. 2004). By contrast, the bullhead is an ambush predator with no known sensory bias in colour perception. The precise importance of parasite coloration versus host-modified behaviour in increasing vulnerability to predators deserves further consideration. Cystacanths of $P$. minutus are bright orange and $P$. minutus-infected gammarids appear, at least to the human eye, even more conspicuous that P. laevis-infected ones. If cystacanth coloration does increase vulnerability to fish predators, then the underconsumption of $P$. minutus-infected preys by bullheads observed in the present study suggests that parasitic manipulation of G. pulex by $P$. minutus may eventually compensate for increased 
conspicuousness. Alternatively, the presence of a yelloworange cystacanths visible through the host's cuticle may not increase the conspicuousness of infected gammarids to bullheads. Clearly, additional experiments are required to evaluate the relative importance of parasite coloration and modified host behaviour in increased trophic transmission to final hosts.

The present study goes beyond earlier findings on parasitic manipulation of host antipredator behaviour (Hechtel et al. 1993; Berdoy et al. 2000; Baldauf et al. 2007; Perrot-Minnot et al. 2007) through adding empirical evidence for specificity (see also Tain et al. 2006). Additional data on risk of predation by nonhosts in other host-parasite associations would be particularly valuable to evaluate the overall importance of specificity in trophic transmission for the evolution of host manipulation by parasites.

\section{Acknowledgments}

N.K. was funded by a doctoral grant from the Ministère de l'Education Nationale, de la Recherche et de la Technologie (MENRT). We thank Sébastien Motreuil for help with field sampling and Raphaël Dodet and Stéphanie Lecuelle for help with lab work.

\section{References}

Andersen, T. H., Friberg, N., Hansen, H. O., Iversen, T. M., Jacobsen, D. \& Krøjgaard, L. 1993. The effects of introduction of brown trout (Salmo trutta L.) on Gammarus pulex L. drift and density in two fishless Danish streams. Archiv für Hydrobiologie, 126, 361-371.

Andersson, K. G., Brönmark, C., Herrmann, J., Malmqvist, B., Otto, C. \& Sjörström, P. 1986. Presence of sculpins (Cottus gobio) reduces drift and activity of Gammarus pulex (Amphipoda). Hydrobiologia, 133, 209-215.

Andreasson, S. 1969. Locomotor activity patterns of Cottus poecilopus Heckel and C. gobio L., (Pisces). Oikos, 20, 78-94.

Bakker, T. C. M., Mazzi, D. \& Zala, S. 1997. Parasite-induced changes in behavior and color make Gammarus pulex more prone to fish predation. Ecology, 78, 1098-1104.

Baldauf, S. A., Thünken, T., Frommen, J. G., Bakker, T. C. M., Heupzl, O. \& Kullmann, H. 2007. Infection with an acanthocephalan manipulates an amphipod's reaction to a fish predator's odours. International Journal for Parasitology, 37, 61-65.

Berdoy, M., Webster, P. P. \& Macdonald, D. W. 2000. Fatal attraction in rats infected with Toxoplasma gondii. Proceedings of the Royal Society of London, Series B, 267, 1591-1594.

Bethel, W. M. \& Holmes, J. C. 1973. Altered evasive behavior and responses to light in amphipods harboring acanthocephalan cystacanths. Journal of Parasitology, 59, 945-956.

Bethel, W. M. \& Holmes, J. C. 1974. Correlation of development of altered evasive behavior in Gammarus lacustris (Amphipoda) harboring cystacanths of Polymorphus paradoxus (Acanthocephala) with the infectivity to the definitive host. Journal of Parasitology, 60, 272-274.

Bethel, W. M. \& Holmes, J. C. 1977. Increased vulnerability of amphipods to predation owing to altered behaviour induced by larval acanthocephalans. Canadian Journal of Zoology, 55, 110-116.

Camp, J. W. \& Huizinga, H. W. 1979. Altered color, behavior and predation susceptibility of the isopod Asellus intermedius infected with Acanthocephalus dirus. Journal of Parasitology, 65, 667-669.
Cézilly, F. \& Perrot-Minnot, M.-J. 2005. Studying adaptive changes in the behaviour of infected hosts: a long and winding road. Behavioural processes, 68, 223-228.

Cézilly, F., Grégoire, A. \& Bertin, A. 2000. Conflict between cooccurring manipulative parasites? An experimental study of the joint influence of two acanthocephalan parasites on the behaviour of Gammarus pulex. Parasitology, 120, 625-630.

Dahl, J., Anders Nilsson, P. \& Pettersson, L. B. 1998. Against the flow: chemical detection of downstream predators in running waters. Proceedings of the Royal society of London, Series B, 265, 1339-1344.

Dodson, S. I., Crowl, T. A., Peckarsky, B. L., Kats, L. B., Covich, A. P. \& Culp, J. M. 1994. Non-visual communication in freshwater benthos: an overview. Journal of the North American Benthological Society, 13, 268-282.

Endler, J. A. 1986. Defense against predators. In: Predator-Prey Relationships: Perspectives and Approach from the Study of Lower Invertebrates (Ed. by M. E. Feder \& G. V. Lauder), pp. 109-134. Chicago: University of Chicago Press.

Fuller, C. A., Rock, P. \& Philips, T. 2003. Behavior, color changes and predation risk induced by acanthocephalan parasitism in the Caribbean termite Nasutitermes acajutlae. Caribbean Journal of Science, 39, 128-135.

Hechtel, L. J., Johnson, C. L. \& Juliano, S. A. 1993. Modification of antipredator behavior of Caecidotea intermedius by its parasite Acanthocephalus dirus. Ecology, 74, 710-713.

Holomuzki, J. R. \& Hoyle, J. D. 1990. Effect of predatory fish presence on habitat use and diel movement of stream amphipod, Gammarus minus. Freshwater Biology, 24, 509-517.

Huhta, A., Muotka, T. \& Tikkanen, P. 2000. Nocturnal drift of mayfly nymphs as a post-contact antipredator mechanism. Freshwater Biology, 45, 33-42.

Hynes, H. B. N. 1954. The ecology of Gammarus duebeni Lilljeborg and its occurrence in fresh water in western Britain. Journal of Animal Ecology, 23, 38-84.

Kats, L. B. \& Dill, L. M. 1998. The scent of death: chemosensory assessment of predation risk by prey animals. Ecoscience, 5, 361-394.

Kennedy, C. R. 1999. Post-cyclic transmission in Pomphorhynchus laevis (Acanthocephala). Folia Parasitologica, 46, 111-116.

Ladich, F. 1989. Sound production by the river bullhead, Cottus gobio L. (Cottidae, Teleostei). Journal of Fish Biology, 35, 531-538.

Levri, E. P. \& Fisher, L. M. 2000. The effect of a trematode parasite (Microphallus sp.) on the response of the freshwater snail Potamopyrgus antipodarum to light and gravity. Behaviour, 137, 11411151.

Lima, S. L. 1998. Non-lethal effects in the ecology of predator-prey interactions. Bioscience, 48, 25-34.

MacNeil, C., Dick, J. T. A. \& Elwood, R. W. 1999. The dynamics of predation on Gammarus spp. (Crustacea: Amphipoda). Biological Review, 75, 375-395.

MacNeil, C., Fielding, N. J., Hume, K. D., Dick, J. T. A., Elwood, R. W., Hatcher, M. J. \& Dunn, A. M. 2003. Parasite altered micro-distribution of Gammarus pulex (Crustacea: Amphipoda). International Journal for Parasitology, 33, 57-64.

Manly, B. F. J. 1974. A model for certain types of selection experiments. Biometrics, 30, 281-294.

Miura, O., Kuris, A. M., Torchin, M. E., Hechinger, R. F. \& Chiba, S. 2006. Parasite alter host phenotype and may create a new ecological niche for snail hosts. Proceedings of the Royal Society of London, Series B, 273, 1323-1328.

Moore, J. 2002. Parasites and the Behavior of Animals. New York: Oxford University Press.

Nickol, B. B. 2005. Parasitic manipulation: should we go anywhere? Behavioural Processes, 68, 201-203. 
Oetinger, D. F. \& Nickol, B. B. 1981. Effects of acanthocephalans on pigmentation of freshwater isopods. Journal of Parasitology, 67, 672-684.

Parker, G. A., Chubb, J. C., Ball, M. A. \& Roberts, G. N. 2003. Evolution of complex life cycles in helminths parasites. Nature, 425, 480-484.

Peacor, S. D. \& Werner, E. E. 1997. Trait-mediated indirect interactions in a simple aquatic food web. Ecology, 78, 1146-1156.

Peckarsky, B. L. \& McIntosh, A. R. 1998. Fitness and community consequences of avoiding multiple predators. Oecologia, 113, 565-576.

Perrot-Minnot, M.-J., Kaldonski, N. \& Cézilly, F. 2007. Increased susceptibility to predation and altered anti-predator behaviour in an acanthocephalan-infected host. International Journal for Parasitology, 37, 645-651.

Plaistow, S. J., Troussard, J.-P. \& Cézilly, F. 2001. The effect of the acanthocephalan parasite Pomphorhynchus laevis on the lipid and glycogen content of its intermediate host Gammarus pulex. International Journal for Parasitology, 31, 346-351.

Poulin, R. 1995. Adaptive" changes in the behaviour of parasitized animals: a critical review. International Journal for Parasitology, 25, 1371-1383.

Rumpus, A. E. 1975. The helminth parasites of the bullhead Cottus gobio (L.) and the stone loach Noemacheilus barbatulus (L.) from the River Avon, Hampshire. Journal of Fish Biology, 7, 469-483.

Seppälä, O., Karvonen, A. \& Valtonen, E. T. 2004. Parasite-induced change in host behaviour and susceptibility to predation in an eye fluke fish interaction. Animal Behaviour, 68, 257-263.

Siegel, S. \& Castellan, N. J. 1988. Nonparametric Statistics for the Behavioral Sciences. New York: McGraw-Hill.

Sih, A. 1987. Prey refuges and predator-prey stability. Theoretical Population Biology, 31, 1-12.
Smith, C., Barber, I., Wootton, R. J. \& Chittka, L. 2004. A receiver bias in the origin of three-spined stickleback mate choice. Proceedings of the Royal Society of London, Series B, 271, 949-955.

Sokal, E. R. \& Rohlf, F. J. 1995. Biometry. New York: W.H. Freeman.

Tain, L., Perrot-Minnot, M.-J. \& Cézilly, F. 2006. Altered host behaviour and brain serotonergic activity caused by acanthocephalans: evidence for specificity. Proceedings of the Royal Society of London, Series B, 273, 3039-3045.

Thomas, F., Adamo, S. A. \& Moore, J. 2005. Parasitic manipulation: where are we and where should we go? Behavioural Processes, 68, 185-199.

Turner, A. M. 1997. Contrasting short-term and long-term effects of predation on consumer habitat use and resources. Behavioral Ecology, 8, 120-125.

Wellnitz, T. A., Giari, L., Maynard, B. J. \& Dezfuli, B. S. 2003. A parasite spatially structures its host population. Oikos, 100, 263-268.

Williams, D. D. \& Moore, K. A. 1985. The role of semiochemicals in benthic community relationships of the lotic amphipod Gammarus pseudolimnaeus: a laboratory analysis. Oikos, 44, 280-286.

Wisenden, B. D. 2000. Olfactory assessment of predation risk in the aquatic environment. Philosophical Transactions of the Royal Society of London, Series B, 355, 1205-1208.

Wisenden, B. D., Chivers, D. P. \& Smith, J. F. 1997. Learned recognition of predation risk by Enallagma damselfly larvae (Odanata, Zygoptera) on the basis of chemical cues. Journal of Chemical Ecology, 23, 137-151.

Wudkevich, K., Wisenden, B. D., Chivers, D. P. \& Smith, J. F. 1997. Reactions of Gammarus lacustris to chemical stimuli from natural predators and injured conspecifics. Journal of Chemical Ecology, 23, 1163-1173. 